\title{
The Relationship between Clinicopathological Features and Expression of Epithelial and Mesenchymal Markers in Spontaneous Canine Mammary Gland Tumors
}

\author{
Kota YOSHIDA $^{1)}$, Saori YOSHIDA ${ }^{1)}$, Nan CHOISUNIRACHON ${ }^{1,2)}$, Tomochika SAITO ${ }^{1)}$, Kaori MATSUMOTO ${ }^{1)}$, \\ Kohei SAEKI ${ }^{1)}$, Manabu MOCHIZUKI ${ }^{1)}$, Ryohei NISHIMURA ${ }^{1)}$, Nobuo SASAKI ${ }^{1)}$ and Takayuki NAKAGAWA ${ }^{1) *}$ \\ ${ }^{1)}$ Laboratory of Veterinary Surgery, Graduate School of Agricultural and Life Sciences, The University of Tokyo, Tokyo 113-8657, Japan \\ ${ }^{2)}$ Department of Veterinary Surgery, Faculty of Veterinary Science, Chulalongkorn University, Henri-Dunant Rd., Pathumwan, Bangkok \\ 10330, Thailand
}

(Received 27 February 2014/Accepted 27 May 2014/Published online in J-STAGE 16 June 2014)

ABSTRACT. It is known that epithelial mesenchymal transition (EMT) contributes to the acquisition of malignant property in human cancers. However, the role of EMT in canine tumors remains to be elucidated. To evaluate the correlation between expression levels of protein markers involved in EMT and clinicopathological characteristics in canine mammary gland tumors, immunohistochemistry using antibodies against ZO-1, E-cadherin, vimentin, N-cadherin and fibronectin was performed on 119 clinical tissue samples. Consequently, loss of ZO-1 and E-cadherin, and gain of vimentin and $\mathrm{N}$-cadherin were more frequently observed in malignant tumors than in benign tumors. However, there was no correlation among expression of these molecules. Univariate and multivariate analysis identified that loss of E-cadherin independently had a low one-year survival rate (adjusted odds ratio: 2.3, $P=0.02$ ). These results suggested that EMT might relate to acquisition of malignancy, and additionally, E-cadherin was strongly correlated with malignant behavior in canine mammary gland tumors. KEY WORDS: canine mammary gland tumors, epithelial mesenchymal transition, immunohistochemistry, prognosis

doi: 10.1292/jvms.14-0104; J. Vet. Med. Sci. 76(10): 1321-1327, 2014

The epithelial-mesenchymal transition (EMT) is a biologic process, which allows a polarized epithelial cell to transform fibroblastic mesenchymal cell phenotype [10]. EMT is a crucial event during physiological and disease processes, including development, fibrosis and cancer [10, 19, 20]. Regarding EMT occurring in cancer progression, tumor cells undergone EMT acquire cell motility and invade the surrounding tissues.

EMT is detected by the loss of epithelial markers, such as ZO-1, E-cadherin and cytokeratin, and up-regulation of mesenchymal markers, such as vimentin, N-cadherin and fibronectin [11]. Several studies have been made on the relationship between EMT and malignancy of human cancers by investigating the expressions of these markers. Vora et al. reported that loss of cytokeratin and gain of vimentin expression predicted biological aggressiveness including recurrence and metastasis in human breast cancer [21].

Canine mammary gland tumors (CMGTs) are the most common tumors occurring in female dogs [4]. Histopathologically, approximately $50 \%$ of CMGTs are diagnosed as malignant $[3,5]$, and a part of such tumors is associated with dismal survival [13]. Several prognostic factors of CMGTs have been identified. Tumor size, lymph node involvement and distant metastasis are major negative prognostic factors in

\footnotetext{
*Correspondence to: Nakagawa T., Laboratory of Veterinary Surgery, Graduate School of Agricultural and Life Sciences, The University of Tokyo, 1-1-1 Yayoi, Bunkyo-ku, Tokyo 113-8657, Japan. e-mail: anakaga@mail.ecc.u-tokyo.ac.jp

(C)2014 The Japanese Society of Veterinary Science

This is an open-access article distributed under the terms of the Creative Commons Attribution Non-Commercial No Derivatives (by-nc-nd) License $<$ http://creativecommons.org/licenses/by-nc-nd/3.0/>.
}

CMGTs. Prognosis in the dogs with malignant CMGT larger than $3 \mathrm{~cm}$ in diameter was obviously worse than that in dogs with malignant CMGT smaller than $3 \mathrm{~cm}$ in diameter [12]. A retrospective study reported that the median postoperative survival of dogs with and without distant metastasis at the time of surgery was 5 months and 28 months, respectively [16].

Several variables acquired from laboratory bench have been also suggested as important prognostic factors of CMGTs. Immunohistochemical studies suggested that detection of some cell proteins correlated to clinicopathological features described above and was also valuable prognostic factors in CMGTs. It has been reported that loss of epithelial marker E-cadherin was significantly related to invasive growth and metastasis in dogs with CMGTs [17]. Expression of the transcription factor Snail, which inhibits transcription of E-cadherin, significantly correlated with histological type, grade and lymphatic invasion in CMGTs tissues [9]. On the other hand, the expression of mesenchymal markers vimentin was occasionally found on tumor cells in CMGTs biopsy samples [7], although the role of this phenomenon has remained to be elucidated. These results are typical changes observed in EMT. Therefore, EMT is thought to have strong relationship with malignancy, such as recurrence, metastasis and survival in CMGTs. However, there is no report evaluating both epithelial and mesenchymal markers inclusively in epithelial tumor cells in CMGTs tissues.

In this study, to clarify the relationship between EMTrelated proteins and clinicopathological features, especially prognosis, we evaluated the protein expressions of both loss of epithelial markers and gain of mesenchymal markers in epithelial tumor cells in CMGTs tissues which we obtained from clinical cases and investigated the relationship with clinicopathological variables of those cases. 
Table 1. Protocol for immunohistochemistry

\begin{tabular}{llll}
\hline & \multicolumn{1}{c}{ Antigen-retrieval } & \multicolumn{1}{c}{ Primary antibody } & \multicolumn{1}{c}{ DAB ${ }^{\mathrm{d})}$} \\
\hline ZO-1 & $121^{\circ} \mathrm{C}, 5 \mathrm{~min}$ in $\mathrm{CB}^{\mathrm{a})}$ & $1: 100,4^{\circ} \mathrm{C}$, over-night & $\mathrm{RT}, 3 \mathrm{~min}$ \\
E-cadherin & $121^{\circ} \mathrm{C}, 5 \mathrm{~min}$ in $\mathrm{CB}^{\mathrm{a})}$ & $1: 150,4^{\circ} \mathrm{C}$, over-night & $\mathrm{RT}, 3 \mathrm{~min}$ \\
Vimentin & $121^{\circ} \mathrm{C}, 5 \mathrm{~min}$ in $\mathrm{CB}^{\mathrm{a})}$ & $1: 50,37^{\circ} \mathrm{C}, 1 \mathrm{hr}$ & $\mathrm{RT}, 1 \mathrm{~min}$ \\
N-cadherin & $121^{\circ} \mathrm{C}, 15 \mathrm{~min}$ in $\mathrm{TB}^{\mathrm{b})}$ & $1: 50,37^{\circ} \mathrm{C}, 50 \mathrm{~min}$ & $\mathrm{RT}, 50 \mathrm{sec}$ \\
Fibronectrin & $\mathrm{RT}^{\mathrm{c}}, 5 \mathrm{~min}$, in proteinase $\mathrm{K}$ & $1: 1,000,37^{\circ} \mathrm{C}, 50 \mathrm{~min}$ & $\mathrm{RT}, 50 \mathrm{sec}$ \\
\hline
\end{tabular}

a) $\mathrm{CB}, 10 \mathrm{mM}$ citrate buffer, pH6.0, b) TB, $10 \mathrm{mM}$ Tris buffer, pH9.0 with $1 \mathrm{mM}$ EDTA, c) RT, room temperature, d) DAB, 3, 3'-diaminobenzidin/hydrogen peroxide solution.
Table 2. Canine mammary gland tumors clinical samples used in this study

\begin{tabular}{lc}
\hline \multicolumn{1}{c}{ Tumor type } & $\mathrm{n}(\%)$ \\
\hline Benign & $10(8.4)$ \\
Simple adenoma & $22(18.5)$ \\
Complex adenoma & $39(32.8)$ \\
Benign mixed tumor & $71(59.7)$ \\
$\quad$ Total & \\
Malignant & $42(35.3)$ \\
Simple carcinoma & $6(5.0)$ \\
Complex carcinoma & $48(40.3)$ \\
\hline \multicolumn{2}{c}{ Total }
\end{tabular}

\section{MATERIALS AND METHODS}

Case: This study included a total of 119 tissue samples from 110 female dogs that were diagnosed as CMGT and underwent surgical resection at the Veterinary Medical Center, the University of Tokyo, between April 1996 and December 2009. Tumor tissues were classified into adenoma $(n=10)$, complex adenoma $(n=22)$, benign mixed tumor $(n=39)$, adenocarcinoma $(n=42)$ and complex adenocarcinoma $(n=6)$ according to the International Histological Classification of Tumors of Domestic Animals of the World Health Organization [14]. When the patient had both benign and malignant CMGTs, malignant CMGT tissue was used in the study. The medical records of applicable cases were reviewed, and clinical data including age, breed, body weight, spay history, anamnestic history, other concurrent disease, experience of lumpectomy, the WHO clinical staging at the time of surgery, operation procedure (unilateral or regional mastectomy), chemotherapy and survival time were collected. Tumor size was calculated as the maximum diameter. Regional lymph node involvement was confirmed by cytopathology, and lung metastasis was confirmed by thoracic radiography. Survival time was defined as the days from surgical resection to death.

Antibody: The primary antibodies used for epithelial markers were rabbit polyclonal anti-ZO-1 (Santa Cruz Biotechnology, CA, U.S.A.) and mouse monoclonal anti-Ecadherin (BD Transduction Laboratories, Lexington, KY, U.S.A.), and those for mesenchymal markers were mouse monoclonal anti-vimentin (Dako Japan, Kyoto, Japan), mouse monoclonal anti-N-cadherin (Dako Japan) and rabbit polyclonal anti-fibronectin (Dako Japan).

Immunohistochemistry: The summary of the procedure is shown in Table 1. Briefly, formalin-fixed paraffin-embedded sections were deparaffinized, followed by antigen epitope retrieval using appropriate methods. Endogenous peroxidase was inactivated by $0.3 \%$ hydrogen peroxide in methanol for $10 \mathrm{~min}$. Then, they were blocked in $0.1 \%$ Tween-20 in PBS (PBS-T) containing 5\% normal goat serum and probed with the primary antibody. After incubation, samples were treated with polymer solution containing HRP-conjugated antibody against mouse immunoglobulin for E-cadherin, vimentin and N-cadherin, and rabbit immunoglobulin for ZO-1 and fibronectin, respectively. Visualizations were done with liquid 3, 3'-diaminobenzidine (DAB)/ hydrogen peroxide solution (Dako Japan) and counterstained with hematoxylin. A normal canine skin tissue was used as positive and negative controls for epithelial and mesenchymal markers, except for $\mathrm{N}$-cadherin. For N-cadherin, normal muscle tissue was used as a positive control.

Evaluation of the EMT markers: The evaluation of epithelial and mesenchymal markers was done by one researcher in a blind fashion without clinical information. For each sample, 3 fields of $\times 200$ magnification were randomly selected from intra-tumoral area. Only stained epithelial tumor cells other than myoepithelium were counted, and the percentage of weak stained and negative cells was calculated for epithelial markers, and the percentage of positive cells was calculated for mesenchymal markers. Regarding mesenchymal markers, samples with less than $1 \%$ positive of expression were defined as negative to avoid the influence of non-specific false positive.

Statistical analysis: Statistical analysis was performed using Excel 2010 or Statview-J 5.0 software, and $P$ value $<0.05$ was considered statistically significant. A chi-square test was used to evaluate the associations between expression of EMT markers and clinicopathological factors. Spearman's rank-correlation coefficient was performed to determine the relationship between two markers. A multiple logistic regression model yielding adjusted odds ratios was used to clarify the availability as prognostic factors. We selected factors showing the association with one-year survival by univariate analysis $(P<0.1)$. Multicollinearity was assessed by variance inflation factor. A variance inflation factor indicates degree of multicollinearity, and values greater than 4 may be a cause of concern.

\section{RESULTS}

Clinical features: The 119 CMGTs tissues (110 dogs) enrolled in this study are summarized in Table 2. This study included following breeds; 20 mongrel, 17 Yorkshire terrier, 14 Maltese, 12 toy poodle, 8 Shih Tzu, 5 miniature dachshund, 5 Shetland sheepdog and 38 other breeds.

Expression of epithelial markers: Expressions of ZO-1 and E-cadherin were observed on the cell membrane and/or cytoplasm (Fig. 1). The number of samples in which weak or negative expression of ZO-1 was observed was significantly larger in dogs $\geq 10$ years ( 21 of 68 ) than in dogs $<10$ years 


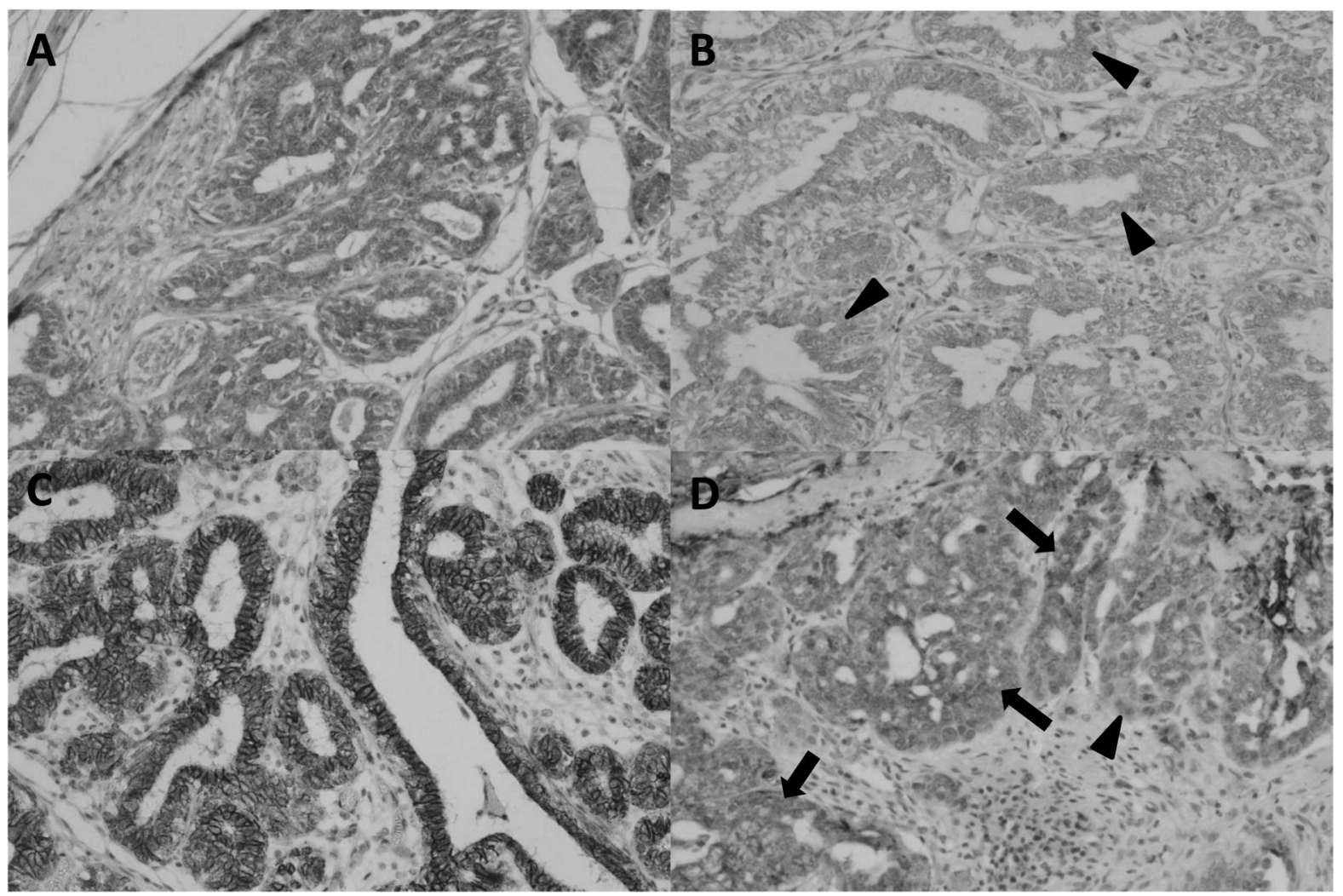

Fig. 1. Representative findings of immunohistochemistry with antibodies against epithelial markers ZO-1 and E-cadherin. (A) Strong expression of ZO-1 was observed in tumor cells. (B) ZO-1 was weakly expressed in tumor cells (arrowheads). (C) E-cadherin was strongly expressed in tumor cells. (D) E-cadherin was weakly expressed in tumor cells (arrows). Occasionally, disappearance of Ecadherin was observed (arrowhead).

( 3 of 51). The number of samples in which weak or negative expression of ZO-1 was observed was significantly larger in dogs with malignant CMGT (21 of 48) than in dogs with benign CMGT ( 3 of 71). The number of samples in which weak or negative expression of E-cadherin was observed was significantly larger in dogs with stages IV and V CMGT (7 of 13) than in dogs with I, II and III grade CMGT (14 of 106). The number of samples in which weak or negative expression of E-cadherin was observed was significantly larger in dogs with malignant CMGT (14 of 48) than in dogs with benign CMGT (7 of 71).

Expression of mesenchymal markers: Mesenchymal markers were observed in the cytoplasm (Fig. 2). The number of samples in which $\geq 1 \%$ positive expression of vimentin was observed was significantly larger in dogs $\geq 10$ years ( 17 of 68 ) than in dogs $<10$ years ( 4 of 51). The number of samples in which $\geq 1 \%$ positive expression of vimentin was observed was significantly larger in dogs with malignant CMGT (19 of 48 ) than in dogs with benign CMGT ( 2 of 71). The number of samples in which $\geq 1 \%$ positive expression of $\mathrm{N}$-cadherin was observed was significantly larger in dogs with malignant CMGT (10 of 48) than in dogs with benign CMGT (1 of 71). There is no significant relationship between expression of fibronectin and clinicopathological characteristics (Table 3).
The correlation between each marker: To evaluate whether expression levels of used markers relate to each other, Spearman's rank-correlation coefficient between two markers was calculated. There is no strong positive correlation between used markers (Table 4).

The relationship between change of EMT markers and one-year survival: Thirteen dogs died of CMGT within a year after surgery. Although necropsy was not allowed in any cases, we judged these dogs died of CMGT because they showed progression of distant metastasis and associated clinical signs. On the other hand, 25 dogs with malignant CMGTs survived more than one year. Table 5 shows the relationship between independent variables including changes in EMT markers and clinicopathological factors and oneyear survival. Independent variables which had associations $(P<0.1)$ with one-year survival were then taken forward to multivariate models. Between these variables, the evidence for multicollinearity was absent, because the variance inflation factor for independent variables was less than 4.0 (data not shown). As shown in Table 6, multiple analysis showed that only loss of E-cadherin was maintained as their independent predictive values (adjusted odds ratio 2.3; $P=0.02$ ). 


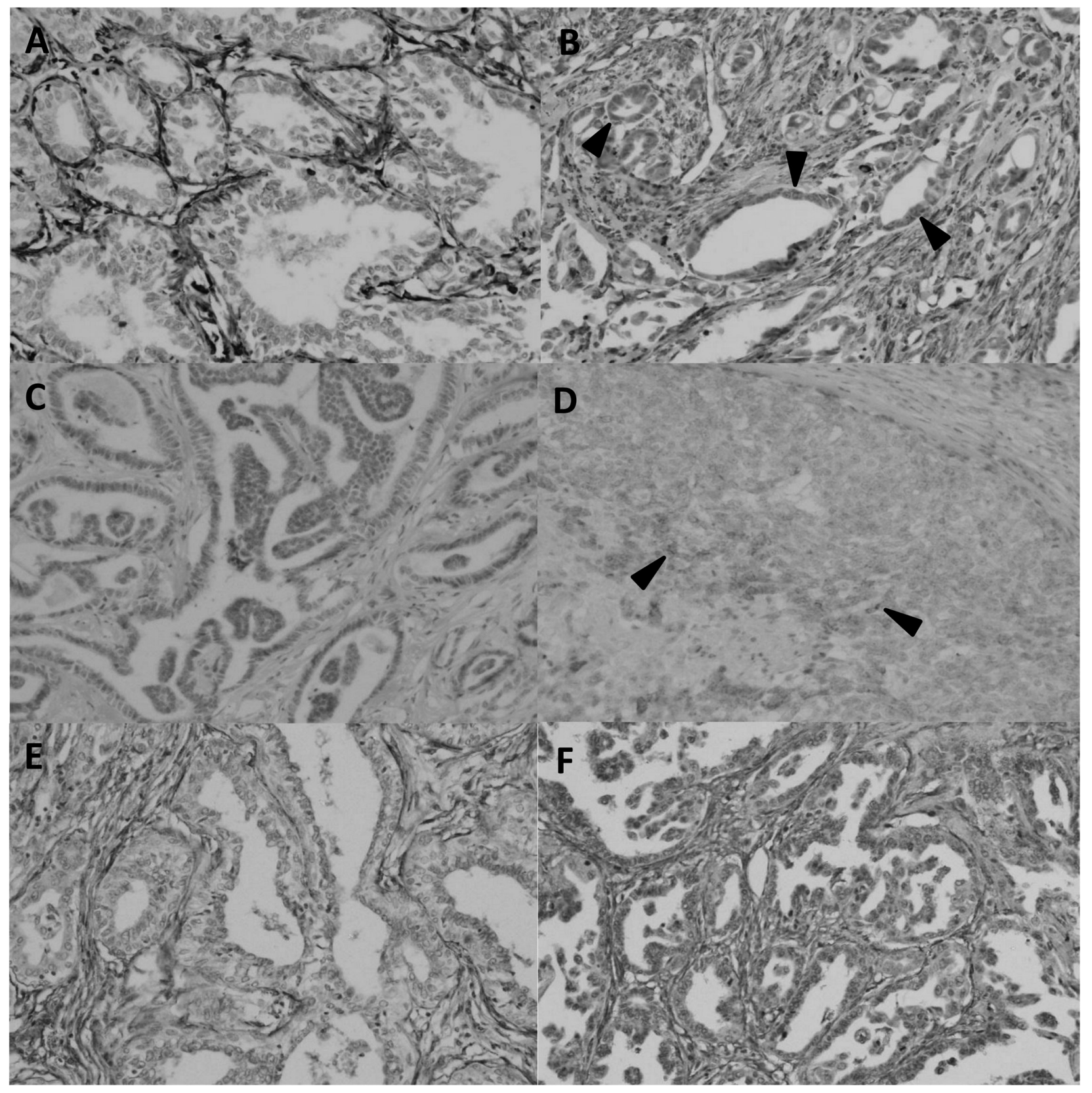

Fig. 2. Representative findings of immunohistochemistry with antibodies against mesenchymal markers, vimentin, N-cadherin and fibronectin. (A) Vimentin was negative in tumor cells. (B) Vimentin was clearly expressed in tumor cells (arrowheads). (C) N-cadherin was negative in tumor cells. (D) Positive expression of N-cadherin was observed in tumor cells (arrowheads). (E) Fibronectin was negative in tumor cells. (F) Fibronectin was expressed in tumor cells.

\section{DISCUSSION}

The loss of epithelial markers and gain of mesenchymal markers were observed in some CMGTs tissues in this study. These results indicate that EMT-like phenomenon occurs in canine tissues as with human breast cancer [6,21]. However, these two changes were not always observed simultaneously in the same tissue, rather, weak correlation was observed between the loss of epithelial markers and gain of mesenchymal markers (Table 4). These results indicate that the mechanisms of loss of epithelial markers and gain of mesenchymal markers may work independently. In the past study, a CMGT cell line stimulated by transforming growth factor- $\beta$ acquired vimentin, whereas did not acquire other markers including E-cadherin, $\beta$-catenin and N-cadherin [23]. This result also advocated that the expression of each marker is 
Table 3. Correlations between change of epithelial and mesenchymal markers and clinicopathological variables

\begin{tabular}{|c|c|c|c|c|c|c|}
\hline & \multicolumn{2}{|c|}{ Loss of } & \multicolumn{3}{|c|}{ Gain of } & \multirow{2}{*}{ Overal } \\
\hline & ZO-1 & E-cadherin & Vimentin & $\mathrm{N}$-cadherin & Fibronectin & \\
\hline \multicolumn{7}{|l|}{ Age (year) } \\
\hline$<10$ & 3 & 5 & 4 & 4 & 29 & 51 \\
\hline$\geq 10$ & 21 & 16 & 17 & 7 & 45 & 68 \\
\hline $\bar{P}$ & $0.002^{\mathrm{b})}$ & 0.09 & $0.03^{\mathrm{a})}$ & 0.89 & 0.3 & \\
\hline \multicolumn{7}{|l|}{ Body weight $(\mathrm{kg})$} \\
\hline$<10$ & 16 & 14 & 13 & 9 & 49 & 82 \\
\hline$\geq 10$ & 8 & 7 & 8 & 2 & 25 & 37 \\
\hline$P$ & 0.99 & 0.99 & 0.61 & 0.53 & 0.42 & \\
\hline \multicolumn{7}{|l|}{ Ovarian status } \\
\hline spayed & 6 & 4 & 5 & 1 & 11 & 16 \\
\hline intact & 18 & 17 & 16 & 10 & 63 & 103 \\
\hline$P$ & 0.13 & 0.63 & 0.24 & 0.98 & 0.76 & \\
\hline \multicolumn{7}{|c|}{ Experience of mastectomy } \\
\hline first & 14 & 15 & 12 & 6 & 55 & 88 \\
\hline experienced & 10 & 6 & 9 & 5 & 19 & 103 \\
\hline$P$ & 0.09 & 0.99 & 0.1 & 0.24 & 0.9 & \\
\hline \multicolumn{7}{|l|}{ Tumor size $(\mathrm{cm})$} \\
\hline$<3$ & 9 & 8 & 7 & 2 & 36 & 60 \\
\hline$\geq 3$ & 8 & 7 & 14 & 2 & 25 & 37 \\
\hline$P$ & 0.23 & 0.32 & 0.14 & 0.054 & 0.62 & \\
\hline \multicolumn{7}{|l|}{ Clinical stage } \\
\hline I-III & 20 & 14 & 17 & 8 & 64 & 106 \\
\hline IV and V & 4 & 7 & 4 & 3 & 10 & 13 \\
\hline$P$ & 0.52 & $0.001^{\mathrm{b})}$ & 0.35 & 0.19 & 0.39 & \\
\hline \multicolumn{7}{|c|}{ Histopathological type } \\
\hline benign & 3 & 7 & 2 & 1 & 46 & 71 \\
\hline malignant & 21 & 14 & 19 & 10 & 28 & 48 \\
\hline$P$ & $<0.001^{\text {b) }}$ & $0.014^{\mathrm{a})}$ & $<0.001^{\mathrm{b})}$ & $0.001^{\mathrm{b})}$ & 0.48 & \\
\hline
\end{tabular}

a) $P<0.05$, b) $P<0.01$.

Table 4. Correlations between epithelial and mesenchymal markers

\begin{tabular}{|c|c|c|c|c|c|}
\hline & \multicolumn{5}{|c|}{ Spearman's rank-correlation coefficient $(\rho)$} \\
\hline & \multicolumn{2}{|c|}{ Loss of } & \multicolumn{3}{|c|}{ Gain of } \\
\hline & $\overline{\mathrm{ZO}-1}$ & E-cadherin & Vimentin & $\mathrm{N}$-cadherin & Fibronectin \\
\hline Loss of $\mathrm{ZO}-1$ & - & $0.34^{\mathrm{b})}$ & $0.34^{\mathrm{b})}$ & $0.21^{\text {a) }}$ & -0.03 \\
\hline Loss of E-cadherin & & - & 0.15 & 0.11 & 0.07 \\
\hline Gain of Vimentin & & & - & $0.19^{\text {a) }}$ & $0.20^{\mathrm{a})}$ \\
\hline Gain of N-cadherin & & & & - & $-0.26^{\mathrm{b})}$ \\
\hline Gain of Fibronectin & & & & & - \\
\hline
\end{tabular}

a) $P<0.05$, b) $P<0.01$.

regulated independently.

The loss of ZO-1 and E-cadherin, and the acquisition of vimentin and $\mathrm{N}$-cadherin were observed in much more malignant CMGT tissues as compared with benign tumor tissues (Table 3). In human tumors, it is understood that EMT is assumed to be a phenomenon that occurs in accordance with the acquisition of a malignancy, such as cell motility, invasive capacity, apoptotic resistance and drug resistance $[10,22]$. The changes of markers observed in this study were similar to EMT in human tumors in that the phenomena mainly occur in carcinoma [8]. Therefore, the investigation of various features associated with EMT given above is important to understanding of tumor malignancy and progression in canine tumors.

On the other side, no significant difference of fibronectin between malignant and benign CMGTs tissues was observed. Positive expression of fibronectin was observed in $64.8 \%$ of benign tissues and $58.3 \%$ of malignant tissues, and no expression in peritumoral normal mammary gland (data not shown). A previous study examined the expression of fibronectin in CMGTs and normal mammary gland [15]. In this study, cytoplasmic staining of fibronectin was observed 
Table 5. Relationship between various parameters and one-year survival

\begin{tabular}{llc}
\hline \multicolumn{1}{c}{ Variables } & $P$ & $\mathrm{OR}^{\mathrm{a})}\left(95 \% \mathrm{CI}^{\mathrm{b})}\right)$ \\
\hline Age & 0.27 & $2.6(0.5-14.5)$ \\
Body weight & 0.69 & $1.3(0.3-5.4)$ \\
Ovarian status & 0.63 & $0.7(0.1-3.6)$ \\
Previous mastectomy & 0.94 & $0.9(0.2-4.0)$ \\
Tumor size & $0.08^{\mathrm{d})}$ & $4.3(0.8-23.7)$ \\
Metastasis & $0.09^{\mathrm{d})}$ & $3.4(0.8-14.9)$ \\
Chemotherapy & 0.14 & $\mathrm{NA}^{\mathrm{c})}$ \\
Operative procedure & $0.09^{\mathrm{d})}$ & $3.4(0.8-14.9)$ \\
Loss of ZO-1 & 0.56 & $1.5(0.4-5.7)$ \\
Loss of E-cadherin & $0.003^{\mathrm{d})}$ & $9.0(1.9-41.7)$ \\
Gain of vimentin & $0.08^{\mathrm{d})}$ & $3.4(0.8-13.8)$ \\
Gain of N-cadherin & 0.83 & $1.2(0.2-6.1)$ \\
Gain of fibronectin & 0.20 & $2.6(0.6-11.9)$ \\
\hline
\end{tabular}

a) OR, odds ratio, b) CI, confidence interval, c) N.A., not available, d) $P<0.1$.

Table 6. The effect of the expression of epithelial and mesenchymal markers on one-year survival

\begin{tabular}{lcc}
\hline \multicolumn{1}{c}{ Variables } & $P$ & Adjusted $\mathrm{OR}^{\mathrm{a})}\left(95 \% \mathrm{CI}^{\mathrm{b})}\right)$ \\
\hline Loss of E-cadherin & $0.02^{\mathrm{c})}$ & $2.3(1.3-70.8)$ \\
Gain of vimentin & 0.17 & $1.4(0.5-30.8)$ \\
\hline
\end{tabular}

a) OR, odds ratio, b) CI, confidence interval, c) $P<0.05$.

in epithelial tumor cells in CMGTs, while no staining in normal mammary tissue. Staining characteristics of fibronectin in the present study was in agreement with these findings. Fibronectin may be correlated with tumor genesis rather than acquisition of malignancy.

In the comparison with clinicopathological variables, age was related to loss of ZO-1 $(P=0.002)$ and acquisition of vimentin (0.03). The median age of benign and malignant groups was 9.5 (range: 5.3-16) and 11.7 (range: 5.3-11.7), respectively. These markers might have correlated with age, because the sensitivity for malignant tissues of $\mathrm{ZO}-1$ and vimentin was higher than that of benign tissues. In contrast, fibronectin did not show the significant relationship. This might occur, because the specificity of fibronectin for the malignancy was low.

Multivariate analysis for one-year survival indicated that loss of E-cadherin was associated with poor prognosis. This result was in accord with the previous studies which suggested the importance of adhesion factors in metastasis [2] and advocated the hypothesis that the acquisition of mesenchymal feature related to tumor malignancy.

However, this study has some limitations. First, we counted only cells that could be recognized as epithelial tumor cells morphologically, however, the tumor cells undergone complete EMT were thought to change their morphology [10]. Remedies are required to evaluate the EMT in tissue samples precisely. Second, we selected 3 fields across the tumoral area to evaluate the expression of each marker. Because the tumor tissue is heterogeneity, it is debatable issue whether 3 fields are enough or not. Furthermore, several studies sug- gested that the EMT occurred frequently at invasive front, but less at intra-tumoral. It has been suggested that a local EMT at invasive front takes place owing to exposition to a different microenvironment, such as stromal fibroblast and increase of EMT regulatory transcription factors via stimulations of various cytokines $[1,18]$. The further investigation including invasive front with enough fields may be necessary to evaluate EMT with more precision.

\section{REFERENCES}

1. Angelucci, C., Maulucci, G., Lama, G., Proietti, G., Colabianchi, A., Papi, M., Maiorana, A., De Spirito, M., Micera, A., Balzamino, O. B., Di Leone, A., Masetti, R. and Sica, G. 2012. Epithelial-stromal interactions in human breast cancer: effects on adhesion, plasma membrane fluidity and migration speed and directness. PLoS ONE 7: e50804. [Medline] [CrossRef]

2. Brabletz, T., Jung, A., Reu, S., Porzner, M., Hlubek, F., KunzSchughart, L. A., Knuechel, R. and Kirchner, T. 2001. Variable beta-catenin expression in colorectal cancers indicates tumor progression driven by the tumor environment. Proc. Natl. Acad. Sci. U.S.A. 98: 10356-10361. [Medline] [CrossRef]

3. Brodey, R. S., Goldschmidt, M. H. and Roszel, J. R. 1983. Canine mammary gland neoplasms. J. Am. Anim. Hosp. Assoc. 19: $61-90$.

4. Egenvall, A., Bonnett, B. N., Ohagen, P., Olson, P., Hedhammar, A. and von Euler, H. 2005. Incidence of and survival after mammary tumors in a population of over 80,000 insured female dogs in Sweden from 1995 to 2002. Prev. Vet. Med. 69: 109-127. [Medline] [CrossRef]

5. Gilbertson, S. R., Kurzman, I. D., Zachrau, R. E., Hurvitz, A. I. and Black, M. M. 1983. Canine mammary epithelial neoplasms: biologic implications of morphologic characteristics assessed in 232 dogs. Vet. Pathol. 20: 127-142. [Medline]

6. Harada, K., Miyake, H., Kusuda, Y. and Fujisawa, M. 2012. Expression of epithelial-mesenchymal transition markers in renal cell carcinoma: impact on prognostic outcomes in patients undergoing radical nephrectomy. BJU Int. 110: E1131-E1137. [Medline] [CrossRef]

7. Hellmén, E. and Lindgren, A. 1989. The expression of intermediate filaments in canine mammary glands and their tumors. Vet. Pathol. 26: 420-428. [Medline]

8. Hugo, H., Ackland, M. L., Blick, T., Lawrence, M. G., Clements, J. A., Williams, E. D. and Thompson, E. W. 2007. Epithelialmesenchymal and mesenchymal-epithelial transitions in carcinoma progression. J. Cell. Physiol. 213: 374-383. [Medline] [CrossRef]

9. Im, K. S., Kim, J. H., Kim, N. H., Yu, C. H., Hur, T. Y. and Sur, J. H. 2012. Possible role of Snail expression as a prognostic factor in canine mammary neoplasia. J. Comp. Pathol. 147: 121-128. [Medline] [CrossRef]

10. Kalluri, R. and Weinberg, R. A. 2009. The basics of epithelialmesenchymal transition. J. Clin. Invest. 119: 1420-1428. [Medline] [CrossRef]

11. Kokkinos, M. I., Wafai, R., Wong, M. K., Newgreen, D. F., Thompson, E. W. and Waltham, M. 2007. Vimentin and epithelial-mesenchymal transition in human breast cancer-observations in vitro and in vivo. Cells Tissues Organs 185: 191-203. [Medline] [CrossRef]

12. Kurzman, I. D. and Gilbertson, S. R. 1986. Prognostic factors in canine mammary tumors. Semin. Vet. Med. Surg. (Small Anim.) 1: 25-32. [Medline] 
13. Misdorp, W. and Hart, A. A. M. 1979. Canine mammary cancer. II. Therapy and causes of death. J. Small Anim. Pract. 20: 395-404. [Medline] [CrossRef]

14. Misdorp, W., Else, R. W., Hellmen, E. and Lipscomb, T. P. 1999. Histological Classification of Mammary Tumors of the Dog and Cat Vol 7. pp.11-29. Armed Forces Institute of Pathology, Washington DC.

15. Peña, L., Nieto, A., Perez Alenza, M. D., Rodriguez, A., Sanchez, M. A. and Castaño, M. 1994. Expression of fibronectin and its integrin receptor alpha 5 beta 1 in canine mammary tumours. Res. Vet. Sci. 57: 358-364. [Medline] [CrossRef]

16. Philibert, J. C., Snyder, P. W., Glickman, N., Glickman, L. T., Knapp, D. W. and Waters, D. J. 2003. Influence of host factors on survival in dogs with malignant mammary gland tumors. $J$. Vet. Intern. Med. 17: 102-106. [Medline] [CrossRef]

17. Sarli, G., Preziosi, R., Tolla, L. D., Brunetti, B. and Benazzi, C. 2004. E-cadherin immunoreactivity in canine mammary tumors. J. Vet. Diagn. Invest. 16: 542-547. [Medline] [CrossRef]

18. Sipos, F. and Galamb, O. 2012. Epithelial-to-mesenchymal and mesenchymal-to-epithelial transitions in the colon. World $J$.
Gastroenterol. 18: 601-608. [Medline] [CrossRef]

19. Thiery, J. P. 2002. Epithelial-mesenchymal transition in tumour progression. Nat. Rev. Cancer 2: 442-454. [Medline] [CrossRef]

20. Tsuji, T., Ibaragi, S. and Hu, G. 2009. Epithelial-mesenchymal transition and cell cooperativity in metastasis. Cancer Res. 69: 7135-7139. [Medline] [CrossRef]

21. Vora, H. H., Patel, N. A., Rajvik, K. N., Mehta, S. V., Brahmbhatt, B. V., Shah, M. J., Shukla, S. N. and Shah, P. M. 2009. Cytokeratin and vimentin expression in breast cancer. Int. J. Biol. Markers 24: 38-46. [Medline]

22. Yao, D., Dai, C. and Peng, S. 2011. Mechanism of the mesenchymal-epithelial transition and its relationship with metastatic tumor formation. Mol. Cancer Res. 9: 1608-1620. [Medline] [CrossRef]

23. Yoshida, K., Saito, T., Kamida, A., Matsumoto, K., Saeki, K., Mochizuki, M., Sasaki, N. and Nakagawa, T. 2013. Transforming growth factor- $\beta$ transiently induces vimentin expression and invasive capacity in a canine mammary gland tumor cell line. Res. Vet. Sci. 94: 539-541. [Medline] [CrossRef] 